\title{
Compact, low-cost NMR spectrometer and probe for dissolution DNP
}

\author{
Albannay, Mohammed M.; Vinther, Joachim Møllesøe; Petersen, Jan Raagaard; Zhurbenko, Vitaliy; \\ Ardenkjær-Larsen, Jan Henrik
}

Published in:

Journal of Magnetic Resonance

Link to article, DOI:

10.1016/j.jmr.2019.04.016

Publication date:

2019

Document Version

Peer reviewed version

Link back to DTU Orbit

Citation (APA):

Albannay, M. M., Vinther, J. M., Petersen, J. R., Zhurbenko, V., \& Ardenkjær-Larsen, J. H. (2019). Compact, low-cost NMR spectrometer and probe for dissolution DNP. Journal of Magnetic Resonance, 304, 7-15. https://doi.org/10.1016/j.jmr.2019.04.016

\section{General rights}

Copyright and moral rights for the publications made accessible in the public portal are retained by the authors and/or other copyright owners and it is a condition of accessing publications that users recognise and abide by the legal requirements associated with these rights.

- Users may download and print one copy of any publication from the public portal for the purpose of private study or research.

- You may not further distribute the material or use it for any profit-making activity or commercial gain

- You may freely distribute the URL identifying the publication in the public portal 


\section{Accepted Manuscript}

Compact, low-cost NMR spectrometer and probe for dissolution DNP

Mohammed M. Albannay, Joachim M.O. Vinther, Jan Raagaard Petersen, Vitaliy Zhurbenko, Jan Henrik Ardenkjaer-Larsen

PII: S1090-7807(19)30082-5

DOI: https://doi.org/10.1016/j.jmr.2019.04.016

Reference: YJMRE 6483

To appear in: Journal of Magnetic Resonance

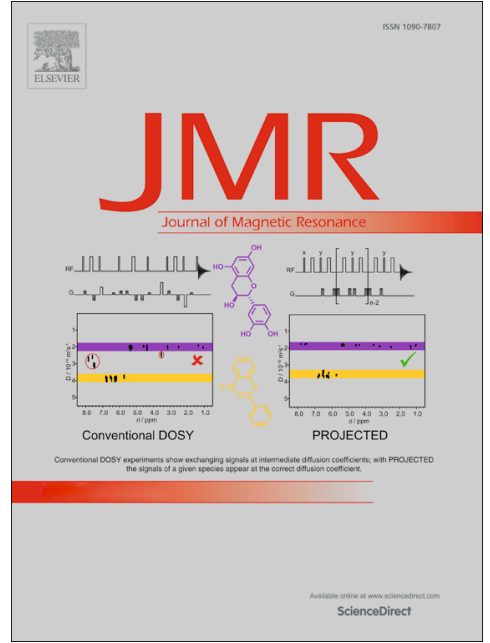

Received Date: $\quad 25$ February 2019

Revised Date: $\quad 24$ April 2019

Accepted Date: $\quad 25$ April 2019

Please cite this article as: M.M. Albannay, J.M.O. Vinther, J. Raagaard Petersen, V. Zhurbenko, J.H. ArdenkjaerLarsen, Compact, low-cost NMR spectrometer and probe for dissolution DNP, Journal of Magnetic Resonance (2019), doi: https://doi.org/10.1016/j.jmr.2019.04.016

This is a PDF file of an unedited manuscript that has been accepted for publication. As a service to our customers we are providing this early version of the manuscript. The manuscript will undergo copyediting, typesetting, and review of the resulting proof before it is published in its final form. Please note that during the production process errors may be discovered which could affect the content, and all legal disclaimers that apply to the journal pertain. 


\section{Compact, low-cost NMR spectrometer and probe for dissolution DNP}

Mohammed M. Albannay ${ }^{1}$, Joachim M. O. Vinther ${ }^{1}$, Jan Raagaard Petersen ${ }^{1}$, Vitaliy Zhurbenko ${ }^{1}$, Jan Henrik Ardenkjaer-Larsen ${ }^{1,2}$

1. Center for Hyperpolarization in Magnetic Resonance, Magnetic Resonance, Department of Health Technology, Technical University of Denmark, Ørsteds Plads, 2800, Kgs. Lyngby, Denmark 2. GE Healthcare, Brøndby, Denmark

Corresponding author:

Jan Ardenkjaer-Larsen

Technical University of Denmark

Ørsted Plads, bldg. 349, room 126

2800 Kgs Lyngby

Denmark

Keywords

dissolution DNP, NMR spectrometer, DNP probe, solid-state NMR 


\section{$\underline{\text { Abstract }}$}

The desire for higher magnetic resonance sensitivity has led to the development of multiple homebuilt and commercial dissolution dynamic nuclear polarization polarizers. The emergence of polarizers capable of variable magnetic field strengths desires a versatile standalone spectrometer and NMR circuit to fulfill detection needs at different frequencies. We present a benchtop NMR spectrometer with duplexer capable of serving high-field solid and liquid state NMR applications up to $450 \mathrm{MHz}$. A detailed view of the employed probe is discussed. Tuning and matching schemes are investigated yielding and experimentally verifying closed-form equations to estimate nutation frequency for a remotely tuned and matched sample coil. 


\section{Introduction}

Dissolution dynamic nuclear polarization (dDNP) has emerged as the leading hyperpolarization technique to address sensitivity challenges in magnetic resonance spectroscopy [1], permitting real-time surveillance of metabolic conversions in-vivo [2] using a myriad of sample complexions. The process relies on unpaired electron spins in paramagnetic molecules that can be aligned to an external magnetic field at a much greater extent than nuclear spins. This alignment is transferable to neighboring nuclei, and since the detectable magnetic resonance (MR) signal is proportional to nuclear polarization, a significant increase in signal-to-noise (SNR) is attainable. Polarization transfer occurs most efficiently at low temperatures near $1 \mathrm{~K}$ inside the so-called dDNP polarizer. The desire for higher MR sensitivity has led to the development of multiple home-built and commercial DNP polarizer systems [3-5]. The rising trend in employing superconducting 'dry magnets' $[5,6]$ with a variable magnetic field, up to $10.1 \mathrm{~T}$, allows the investigation of DNP physics in different experimental conditions. Accordingly, versatile hardware is required to fulfill the needs at different values of the magnetic field. The detection step of the DNP experiment includes two fundamental components, the NMR spectrometer and the detection circuit.

Monitoring the polarization build-up is crucial for verifying the efficiency of the dynamic nuclear polarization (DNP) process. NMR detection is often accomplished using low-cost benchtop NMR spectrometers. Nevertheless, their limited capabilities (e.g. low frequency, single channel, etc.) do not allow for more advanced NMR pulse sequences in the solid-state (e.g. cross polarization) nor monitor high gamma nuclei (e.g. ${ }^{1} \mathrm{H}$ ) at higher magnetic fields. Two trends have dictated the development of NMR spectrometers in recent years. Firstly, the brute-force pursuit for greater NMR sensitivity and increasingly stronger magnets [7] has led to the development of highfrequency rack spectrometers. Secondly, the need for offsite experimentation has resulted in compact, benchtop spectrometers, but low-frequency due to a paired permanent magnet [8]. The two diverging trends have slowed development for compact spectrometers capable of serving highfield NMR applications at frequencies of hundreds of $\mathrm{MHz}$. Technological advancements in embedded electronics and field programmable gate arrays (FPGA) has resulted in solutions such as the OPENCORE NMR $[9,10], \mathrm{Kea}^{2}$ (Magritek, New Zealand), Scout (Tecmag Inc, TX, USA) and Pulse (RS ${ }^{2} D$, France) spectrometers.

We propose a solution based on a commercially available benchtop spectrometer with a signal processor and transceiver that would operate up to $450 \mathrm{MHz}$. The control software is easily programmable and offers a library of basic NMR sequences. The spectrometer is furnished with an integrated custom-built duplexer and a high-power pulse amplifier (HPA) to fulfill the requirements needed during the DNP process. 
The second component to consider when operating a variable field magnet is the NMR circuity. Detection of nuclear spin at a particular Larmor frequency is facilitated by the reactive tune and match (TM) elements coupled to the sample coil. NMR probes often host multiple resonance circuitry supplemented by externally tuneable elements to offer a broad frequency bandwidth. In a dDNP probe, remote TM schemes offer the closest experience where users can investigate multiple nuclei at different frequencies by manipulating TM element reactance at room temperature outside the cryostat. This advantage is forfeited by local TM schemes that require probe withdrawal from the cryogenic environment to modify the detection frequency. Widely used ceramic capacitors are prone to thermal fracturing and failure due to temperature cycling between cryogenic and room temperatures. Nonetheless, improved sample coil sensitivity is well reported for local TM schemes [11-14]. In this work, we investigate the difference in sensitivity and derive and experimentally verify an analytical closed-form method of determining the nutation frequency generated in a sample coil employing both remote and local TM schemes.

\section{Materials and Methods}

\section{Solid-state DNP polarizer}

Experiments are performed on a home-built DNP polarizer similar to that described in [15]. The DNP polarizer magnet (Magnex Scientific, Oxford, UK) is charged to 6.7 T. The microwave source is based on an actively multiplied Gunn diode oscillator (Quinstar Technology Inc., CA, USA) and a 200X2R4 frequency doubler (VDI, Charlottesville, VA, USA). A NI-USB-6525 data acquisition device (National Instruments, TX, USA) controls the microwave source tuning frequency and power attenuation. The source output center frequency is $187.8 \mathrm{GHz}$ with a tuning range of \pm 0.5 $\mathrm{GHz}$ and a maximum output of $58.5 \mathrm{~mW}$. The magnet has a helium flow variable temperature insert (VTI) capable of reaching a sample space temperature of $1.2 \mathrm{~K}$. The dDNP probe (Figure 1) consists of an ISO-F100 flange (Kurt J. Lesker company, USA) that accommodates a $790 \mathrm{~mm}$ $316 \mathrm{~L}$ stainless steel sample tube at its center, with an inner and outer diameter $11.8 \pm 0.1 \mathrm{~mm}$, $12.7 \pm 0.1 \mathrm{~mm}$, respectively. A $780 \mathrm{~mm} 316 \mathrm{~L}$ stainless steel circular waveguide with an inner diameter $4.16 \pm 0.02 \mathrm{~mm}$ couples the output of the microwave source to a cylindrical copper cavity with the inner diameter $27 \pm 0.1 \mathrm{~mm}$ and interior height $30 \pm 0.1 \mathrm{~mm}$ located at the end of the sample tube. The waveguide inlet is centered $9 \mathrm{~mm}$ off the irradiation cavity center axis, while the sample coil and sample tube are centered $1 \mathrm{~mm}$ in the opposing direction. A UT141SS-C-P semirigid stainless-steel coaxial cable couples the sample coil to a spectrometer via a hermetic bulkhead SMA connector to gain access through the ISO-F100 flange. Three Allen-Bradley resistors stacked $1 \mathrm{~cm}$ vertically apart, and a Cernox CX1030 temperature sensor (Lakeshore Equipment, CA, USA) placed above the cavity measure the level of liquid helium and VTI 
temperature, respectively via Fischer connectors on the ISO-F100 flange. The sample tube extrudes by $30 \mathrm{~mm}$ above the ISO-F100 flange and terminates into a KF-16 flange forming the sample loading port. A gate valve (VAT, Switzerland) and airlock adapted from the SPINlab DNP polarizer [16] are mounted above the sample loading port.

\section{Sample preparation}

A $100 \mu \mathrm{L} 4.5 \mathrm{M}\left[1{ }^{13} \mathrm{C}\right]$ urea dissolved in 5:4:1 glycerol- $\mathrm{d}_{8}: \mathrm{D}_{2} \mathrm{O}: \mathrm{H}_{2} \mathrm{O}(\mathrm{v}: \mathrm{v}) 40 \mathrm{mM}$ TEMPOL is pipetted into a cylindrical polytetrafluoroethylene (PTFE) threaded vial with a height $35 \pm 0.5 \mathrm{~mm}$, inner diameter $4 \pm 0.1 \mathrm{~mm}$ and wall thickness $1 \pm 0.1 \mathrm{~mm}$. A threaded cap seals the top of the vial [17]. The co-axial tubing of a fluid path as described in [16] is attached to the cap using a UV-cured adhesive Dymax 215-C (Dymax Corp, CT, USA). The sample vial is flash-frozen by immersing the vial in liquid nitrogen to mitigate sample crystallization and purged with gaseous helium via the fluid path to displace the vial atmosphere before loading into the DNP polarizer. A microwave frequency sweep identified maximum positive DNP enhancement is obtained irradiating at $188.06 \mathrm{GHz}$ with a maximum frequency change of $\pm 50 \mathrm{MHz}$ and rate $1 \mathrm{kHz}$.

\section{Benchtop NMR spectrometer}

The benchtop NMR spectrometer extends the commercially available $\mathrm{Kea}^{2}$. The spectrometer used in this work employs two modules (refer to Figure 2). The first is a digital signal processor (DSP) that executes user-programmed pulse sequences and controls peripheral units in the Kea ${ }^{2}$ system. The proprietary software package, Prospa, facilitates further sequence development. The second module is a digital transceiver with two transmit channels and one receive channel. The spectrometer is equipped with a TwinPulse 400 amplifier (Tomco Technologies, Australia) to enable high power pulsing and offers two output channels, up to $100 \mathrm{~W}$ for $200-650 \mathrm{MHz}$ and up to $300 \mathrm{~W}$ for 5-300 MHz. A duplexer module was designed and fabricated on two FR-4 printed circuit boards and accommodates a transmit/receive (T/R) switch, switch driver circuit and low noise amplifier (LNA) that operates up to $450 \mathrm{MHz}$. Six coaxial ports are present on the front panel (3 rack units $(13.3 \mathrm{~cm})$ and 21 height pitch units $(10.7 \mathrm{~cm})$ ) for high power amplifier (HPA) input, probe, HPA blanking and LNA output. The duplexer scattering parameters, transient switching response and gain and noise figure are characterized on the bench using a E5062A vector network analyser (Keysight Technologies, CA, USA), RTO 1044 oscilloscope (Rhode \& Schwarz, Germany) and a E4440A spectrum analyzer calibrated with a $346 \mathrm{~B}$ noise source (Keysight Technologies, CA, USA). 


\section{Transceiver}

Both transmitter channels are capable of producing 14-bit sinusoidal waveforms up to $400 \mathrm{MHz}$ with an output power of $0 \mathrm{dBm}$ into $50 \Omega$. However, the onboard synthesizer can produce higher frequencies at lower bit resolution. The receiver channel comprises of a $100 \mathrm{MS} / \mathrm{s}, 16$-bit analog to digital converter (ADC). The digital receiver is based on an FPGA and has a $100 \mathrm{~dB}$ dynamic range.

\section{$T / R$ switch}

Switching between pulse and acquisition modes is facilitated by MA4P504-1072T PIN diodes D1, D2 and D3 (MACOM Technology Solutions, MA, USA) illustrated in Figure 3. An exchangeable N/4 cable couples the probe port to the LNA to improve isolation during pulse mode. A $5 \mathrm{~V}$ forward bias voltage applied when pulsing causes all diodes to conduct. In turn, the LNA is isolated from the power amplifier and couples to the probe port. PIN diode conduction is seized during acquisition mode due to a $-15 \mathrm{~V}$ reverse bias voltage. Consequently, coupling the probe port to the LNA input while isolating the power amplifier. The bias current is limited by $39 \Omega$ resistors and connects via $1.3 \mu \mathrm{H}$ RF choke (RFC) inductors.

\section{$T / R$ switch driver}

A TTL signal generated from the DSP is coupled via the backplane and is buffered by a $74 \mathrm{HC} 240$ inverting driver (U2) as illustrated in Figure 4. A -15 V rail provides the reverse bias voltage, while an LM340MP-5.0 (U1) regulates the $8 \mathrm{~V}$ rail to provide a $5 \mathrm{~V}$ forward bias voltage. In pulse mode, the P-channel MOSFET (Q1) source-drain conductivity is high when a low-level voltage is present at its gate, causing the bias node voltage to rise to $5 \mathrm{~V}$. In acquisition mode, a high-level voltage from U2 buffers through the common-base transistor amplifier (Q3) and distributes across R6. A positive gate-source voltage causes N-channel MOSFET (Q2) source-drain conductivity to rise, causing the bias node voltage to fall to $-15 \mathrm{~V}$.

\section{Low noise amplifier}

The duplexer employs an AU-2A-150 LNA (L3 Narda-MITEQ, NY, USA) that offers an average gain of $34.5 \mathrm{~dB}$ with a typical noise figure of $1.4 \mathrm{~dB}$ up to $500 \mathrm{MHz}$. The amplifier is supplied with $15 \mathrm{~V}$ from the $\mathrm{Kea}^{2}$ backplane and could handle a maximum input power of $13 \mathrm{dBm}(\mathrm{CW})$. Three pairs of crossed diodes SMP1340-075LF (Skyworks Solutions, MA, USA) are placed at the LNA input to mitigate saturation thus reducing receiver dead time. 


\section{RF characterization}

\section{Sample coil}

A parallel Alderman-Grant coil machined from a hardened copper tube with a height $25 \pm 0.1 \mathrm{~mm}$, outer diameter $15 \pm 0.1 \mathrm{~mm}$ and inner diameter $13 \pm 0.1 \mathrm{~mm}$ sits inside the overmoded copper cavity. Two parallel slots form an angle of $93^{\circ}$ and are present on both sides of the coil as illustrated inFigure 5. A single $1 \pm 0.1 \mathrm{~mm}$ slit is cut exactly $2 \mathrm{~mm}$ from the coil's top ring, exposing two terminals for coil excitation via a coaxial cable. Spatial variation in the linearly plarized magnetic field amplitude, $B_{1}$, is depicted in Figure 5 computed by the commercial EM simulator package, CST Microwave Studio 2018 (Dassault Systèmes, France). Even for a large sample (cylinder; $r=5 \mathrm{~mm}$ and $h=10 \mathrm{~mm}$ ), $B_{1}$ variation across the volume amounts to $4.7 \%$. The deembed sample coil impedance $\left(Z_{A}=R_{A}+j X_{A}\right)$ measured using a MS2024B vector network analyzer (Anritsu Corporation, Japan) is $0.032+\mathrm{j} 24.9 \Omega$ and $0.015+\mathrm{j} 6.3 \Omega$ for ${ }^{1} \mathrm{H}(285.55 \mathrm{MHz})$ and ${ }^{13} \mathrm{C}(71.8 \mathrm{MHz})$, respectively.

Transmission line analysis and field estimation.

A circuit model of the remotely TM sample coil as present in the DNP polarizer is outlined in Figure 6. The UT141SS-C-P coaxial cable extends $l_{1}=780 \mathrm{~mm}$ from the coil to the hermetic SMA adapter located on the probe's top flange. To ensure the transformed coil impedance $\left(Z_{B}\right)$ remains inductive, an RG316 coax cable of length $l_{2}=100 \mathrm{~mm}$ or $l_{2}=640 \mathrm{~mm}$ is used when investigating ${ }^{1} \mathrm{H}$ or ${ }^{13} \mathrm{C}$ nuclei, respectively. Using transmission line theory [18], the input impedance is defined:

$$
Z_{B}=R_{B}+j X_{B}=Z_{0} \cdot \frac{Z_{A}+Z_{0} \tanh \left(l_{1}\left(\alpha_{1}+j \beta_{1}\right)+l_{2}\left(\alpha_{2}+j \beta_{2}\right)\right)}{Z_{0}+Z_{A} \tanh \left(l_{1}\left(\alpha_{1}+j \beta_{1}\right)+l_{2}\left(\alpha_{2}+j \beta_{2}\right)\right)}
$$

where $\alpha$ denotes attenuation constant, $\beta$ propagation constant and subscript index refers to the respective transmission line. Two EM25HV high-Q trimmer capacitors (Knowles Voltronics, Norwich, UK) TM the load impedance. The tuning $\left(C_{t}\right)$ and matching $\left(C_{m}\right)$ element values are found by solving the matching conditions [18]:

$$
\begin{gathered}
B=\frac{X_{B} \pm \sqrt{\frac{R_{B}}{Z_{0}}} \sqrt{R_{B}^{2}-R_{B} Z_{0}+X_{B}^{2}}}{R_{B}^{2}+X_{B}^{2}} \\
C_{t}=B / \omega
\end{gathered}
$$




$$
\begin{gathered}
X=\frac{1}{\omega C_{t}}+\frac{X_{B} Z_{0}}{R_{B}}-\frac{Z_{0}}{R_{B} B} \\
C_{m}=1 / \omega X
\end{gathered}
$$

To satisfy the conditions using capacitive elements, equations (2) and (3) are only valid when $B$ and $X$ are positive, therefore an appropriate sign is to be chosen in equation (3). Subsequently, the input impedance of the parallel LC resonant circuit is defined as:

$$
Z_{C}=\frac{1}{j \omega C_{t}}+\frac{1}{Z_{B}}
$$

and can be matched to the HPA impedance $\left(R_{g}\right)$ such that:

$$
Z_{\text {in }}=\frac{-j}{\omega C_{m}}+Z_{C}=R_{g}=50 \Omega
$$

Voltage and current distributions across the circuit are determined using circuit theory to identify the current flowing through the coil and nutation frequency $\left(v_{1}\right)$ for a given excitation power. First, the voltage across the HPA terminals and the current flowing to the NMR circuity are defined:

$$
\begin{gathered}
V_{g}=\sqrt{2 P_{i n} Z_{i n}} \\
i_{g}=V_{g} / Z_{i n}
\end{gathered}
$$

where $P_{\text {in }}$ denotes the power accepted by the circuit. Second, voltage and current distributions across the parallel LC resonant circuit are found:

$$
\begin{gathered}
V_{C}=V_{g} \frac{Z_{C}}{Z_{C}+j X} \\
i_{C}=V_{C} / Z_{C}
\end{gathered}
$$

Third, the amplitude voltage of an excitation pulse coupled through both transmission lines is expressed as:

$$
V_{0}^{+}=\frac{V_{C}}{\exp \left(l_{1}\left(\alpha_{1}+\mathrm{j} \beta_{1}\right)+\Gamma_{B} l_{2}\left(\alpha_{2}+\mathrm{j} \beta_{2}\right)\right)}
$$

where $\Gamma_{B}=\left(Z_{B}-Z_{0}\right) /\left(Z_{B}+Z_{0}\right)$. Finally, the sample coil voltage and current can be determined:

$$
\begin{gathered}
V_{\mathrm{A}}=V_{0}^{+}\left(1+\Gamma_{A}\right) \\
i_{\mathrm{A}}=\mathrm{V}_{\mathrm{A}} / Z_{A}
\end{gathered}
$$


where $\Gamma_{A}=\left(Z_{A}-Z_{0}\right) /\left(Z_{A}+Z_{0}\right)$. The $v_{1}$ is directly proportional to the coil current and can be found in the homogenous region of the coil as:

$$
v_{1}=\frac{1}{2} B_{1} i_{A} \gamma
$$

where $\gamma$ denotes the gyromagnetic ratio.

\section{Pulse calibration}

Performing a traditional $90^{\circ}$ pulse calibration in static solid-state NMR is challenging due to the need for a long pulse duration (hundreds of $\mu$ s) for low $Q$ probes. A long pulse would only partially excite the broad NMR spectrum and use of high-powered pulse will inevitably lead to arcing inside the cryostat. This is especially problematic when considering volumetrically large samples, where achieving a high $B_{1}$-field is technically challenging. Alternatively, the hyperpolarized sample is exploited to experimentally verify $v_{1}$. A series of spectra acquired with a repetition time longer than $T_{2}$ and much shorter than $T_{1}$ is fitted using:

$$
\mathrm{M}(n)=\mathrm{M}_{0}(\cos \theta)^{n}
$$

where $\mathrm{M}_{0}$ denotes the initial magnetization, $\theta$ pulse flip angle in radians and $n$ number of pulses. Once, the flip angle is identified, the nutation frequency is calculated as $v_{1}=\theta / 2 \pi \tau$, where $\tau$ is the pulse duration. Moreover, this method is preferable due to the prohibitively long relaxation time necessary to achieve thermal equilibrium at low temperature required by traditional nutation experiments. The field is measured for both ${ }^{1} \mathrm{H}$ and ${ }^{13} \mathrm{C}$ spectra for varying transmit powers.

\section{DNP-NMR experiments}

The $\mathrm{Kea}^{2}$ NMR performance is benchmarked against a Direct Drive (DD) spectrometer (Varian Inc, $\mathrm{CA}, \mathrm{USA}$ ) by acquiring ${ }^{1} \mathrm{H}$ and ${ }^{13} \mathrm{C}$ spectra on a hyperpolarized sample. The sample was cooled in a helium bath to $1.2 \mathrm{~K}$ and irradiated with microwaves for $10 \mathrm{~min}$. Next two ${ }^{1} \mathrm{H}$ spectra are acquired using both the benchtop and DD spectrometers. The process is repeated for the acquisition of two ${ }^{13} \mathrm{C}$ spectra after allowing 30 minutes of microwave irradiation. $2.4^{\circ}$ and $1.3^{\circ}$ excitation pulses were employed for acquiring ${ }^{1} \mathrm{H}$ and ${ }^{13} \mathrm{C}$ spectra, respectively. Spectra consist of 4096 samples with a spectral width of $1 \mathrm{MHz}$ on the benchtop and $1.25 \mathrm{MHz}$ on the $\mathrm{DD}$ (receiver gain set to $0 \mathrm{~dB}$ ). A line broadening of $3 \mathrm{kHz}$ was applied to the captured spectra in post-processing. 


\section{$\underline{\text { Results }}$}

In pulse mode all PIN diodes are forward biased and source $64 \mathrm{~mA}$ each, resulting in a series impedance of $0.5 \Omega$. The insertion loss between the HPA and probe is $<0.66 \mathrm{~dB}$, while isolation between the HPA and LNA is $>36 \mathrm{~dB}$ as recorded in Figure 7. In acquisition mode, the insertion loss between the probe and LNA is limited to $<0.87 \mathrm{~dB}$. RFC inductors contribute the majority of the observed insertion loss between the HPA and probe for frequencies below $50 \mathrm{MHz}$. On the other hand, crossed diodes limit the operation of the duplexer beyond $450 \mathrm{MHz}$ due to rising insertion loss between the probe and LNA.

The transient diode voltage switching from acquisition and pulse mode is illustrated in Figure 8. Transitioning from acquisition to pulse mode takes $690 \mathrm{~ns}$, which is the time needed for the diode voltage to reach steady state forward bias conditions. The diode voltage overshoots by $0.6 \mathrm{~V}$ for 100 ns due to the rapid increase in current flow. To transition into acquisition mode, the reverse bias voltage expels charge carriers from the PIN diodes. The storage time takes 550 ns and causes a significant drop in diodes voltage. Afterward, the voltage exponentially reduces further until steady state reverse bias is reached and the diodes cease to conduct. Overall, the total time required to switch into acquisition time is $\sim 2400 \mathrm{~ns}$.

Duplexer gain and noise figure measurements between the probe and LNA output ports during acquisition mode (i.e. $V_{\text {bias }}=-15 \mathrm{~V}$ ) is illustrated in Figure $8 \mathrm{c}$ and $\mathrm{d}$, respectively. Also shown are the DD duplexer gain and noise figure measurement for comparison. The LNA provides a steady gain of $33 \pm 1.5 \mathrm{~dB}$ with a noise figure of $1.7 \pm 0.6 \mathrm{~dB}$. The duplexer noise figure includes the LNA contribution and insertion loss $\left(S_{32}\right)$ which amounts to $0.7 \pm 0.32 \mathrm{~dB}$.

Receiver noise floor measurements at $290 \mathrm{~K}$ yielded $-108 \mathrm{dBm} / \mathrm{Hz}$ and $-140 \mathrm{dBm} / \mathrm{Hz}$ for the benchtop and DD spectrometers, respectively. Acquired hyperpolarized ${ }^{1} \mathrm{H}$ and ${ }^{13} \mathrm{C}$ spectra and free induction decay (FID) are shown in Figure 9. The spectrum SNR was calculated as the ratio between the amplitude of the peak and the root-mean-square of a signal-free area of the spectrum. The $\mathrm{Kea}^{2}$ records an SNR value of 1170 for ${ }^{1} \mathrm{H}$ and 88 for ${ }^{13} \mathrm{C}$ spectra, while the DD yielded 1276 and 132 for the aforementioned nuclei.

The estimated nutation frequency per squareroot power for a transmission line with an attenuation $\alpha$ and length between 0 and $1000 \mathrm{~mm}$ is illustrated in Figure 10. Maximum nutation frequency is achieved when the transmission line length is $0 \mathrm{~mm}$ (i.e. local TM). The frequency reduces to half with the addition of a $100 \mathrm{~mm}$ transmission line section and with $90 \%$ when extending the line to $250 \mathrm{~mm}$. In the case of the dDNP probe which relies on a transmission line length of $1420 \mathrm{~mm}$ or $880 \mathrm{~mm}$ depending on the nucleus. 


\section{Discussion}

The $\mathrm{Kea}^{2}$ offers a versatile user-programmable standalone spectrometer that possesses the capacity to integrate multiple modules on-board. The DSP and transceiver are electronically well equipped for operation up to several hundred $\mathrm{MHz}$ to service the needs of high field NMR applications. As such, the duplexer was developed for a similar operational bandwidth with solidstate NMR performance in consideration. Given the low insertion loss between the HPA and probe, in conjunction with the high isolation between the HPA and LNA, maximum amplifier power can be transferred to the NMR circuit without concerns of damaging or saturating the LNA. In pulsing mode, PIN diodes are forward biased $2 \mu \mathrm{s}$ before pulsing on the benchtop spectrometer. Isolation between the HPA and LNA can be further improved by reducing parasitic inductance from the diode packaging. While insertion losses can be curbed at lower frequencies by raising the RFC inductance.

Switching to acquisition mode, the PIN diode voltage requires approx. 3.5 times longer to reach steady state reverse bias. However, the duplexer enters acquisition mode much sooner as the PIN diode impedance rises to tens of Ohms once storage time has elapsed, which occurs in a fifth of the total settling time. While additional crossed diodes assist reduce LNA saturation during pulsing, parasitic capacitance in the diode packaging increases insertion loss between the probe and LNA input at higher frequencies. Both the $\mathrm{DD}$ and benchtop spectrometer acquired similar FIDs that have been oversampled and quantized via a 16-bit ADC, with both duplexers hosting PIN diodes with similar lifetimes biased with similar source currents and bias voltages.

Compared to the benchtop spectrometer, the DD achieved a $10 \%$ and $50 \%$ higher SNR when measuring ${ }^{1} \mathrm{H}$ and ${ }^{13} \mathrm{C}$ spectra, respectively, which can be attributed to the inherent lower receiver noise floor of the DD. The benchtop SNR can be improved with a second stage amplifier; however, the high receiver noise floor would limit the available dynamic range and overall improvement.

TM scheme design flexibility is limited when implemented on dDNP probes due to the low temperature and atmosphere of the cryostat. When considering a remote TM scheme, the dimensions of the polarizer dictates the transmission line length and consequently the resonant circuit $Q$-factor. The transmission line dominates the total losses in the resonant circuit. Inductive and resistive contributions per unit length from additional line sections eventually result in a constant $Q$ - factor $\left(Q=\omega_{0} L / R\right)$.. Investigating the achievable nutation frequency with respect to the line length indicates a clear distinction between the two TM schemes, local and remote, due to the rapidly decreasing field strength. Coupling the sample coil to the $50 \Omega$ transmission line results in a high standing wave ratio $\left(\operatorname{SWR}=\left(1+\left|\Gamma_{\mathrm{A}}\right|\right) /\left(1-\left|\Gamma_{\mathrm{A}}\right|\right)\right)$ and significant higher losses than expected for a low-loss line. 
The only solution to reduce this loss is by pre-matching a tuned sample coil before connecting it to the transmission line (i.e. local TM), thus theoretical yielding 14 and 20 fold increase in $v_{1}$ for ${ }^{1} \mathrm{H}$ and ${ }^{13} \mathrm{C}$, respectively. However, placing lumped elements near the sample coil is impractical and often inconvenient if sample space is at a premium. Preliminary tests employing a local TM scheme that consists of a tuned coil that is pre-matched via a $25 \mathrm{~mm}$ low-loss line (extending out of the cavity) yielded between a 10-15 fold increase in $v_{1}$, for the aforementioned nuclei [19].

\section{Conclusion}

The $\mathrm{Kea}^{2}$ is a modular benchtop spectrometer capable of supporting high field applications. The spectrometer with the integrated duplexer offers a solution to measure nuclear spin polarization in DNP polarizer systems up to $450 \mathrm{MHz}$. The bench spectrometer achieved $90 \%$ and $50 \%$ the SNR value of that from a dedicated full rack spectrometer for ${ }^{1} \mathrm{H}$ and ${ }^{13} \mathrm{C}$ spectra measured at $6.7 \mathrm{~T}$. The spectrometer could accommodate both solid and liquid state spectroscopy including advanced pulse sequences for a significantly reduced cost. Moreover, there is additional capacity on-board the spectrometer to install an integrated power amplifier to further reduce the spectrometer footprint.

Remote TM schemes provides great convenience for exploring multiple nuclei without the need of withdrawing the dDNP probe from the polarizer. The derived closed-form method quantifies the achievable nutation frequency any given transmit power and transmission line length. In the discussed example, remote TM scheme reduced the observed $\nu_{1}$ by a factor of 14 and 20 for ${ }^{1} H$ and ${ }^{13} \mathrm{C}$, respectively from the theoretical maximum achievable with a local TM scheme. $v_{1}$ estimation is based on a simple circuit analysis technique and is a complimentary evaluation aid to the coil perturbation method [20] and calibrated single or dual loop probe [21].

\section{Acknowledgment}

This work is supported by the European Union's Horizon 2020 research and innovation programme under the Marie Sklodowska-Curie grant agreement No. 642773 and the Danish National Research Foundation (DNRF 124). 


\section{$\underline{\text { References }}$}

[1] J.H. Ardenkjaer-Larsen, On the present and future of dissolution-DNP, J. Magn. Reson. 264 (2016) 3-12. doi:10.1016/j.jmr.2016.01.015.

[2] K. Golman, R. in 't Zandt, M. Thaning, Real-time metabolic imaging., Proc. Natl. Acad. Sci. U. S. A. 103 (2006) 11270-5. doi:10.1073/pnas.0601319103.

[3] M. Batel, M. Krajewski, A. Däpp, A. Hunkeler, B.H. Meier, S. Kozerke, M. Ernst, Dissolution dynamic nuclear polarization efficiency enhanced by Hartmann-Hahn cross polarization, Chem. Phys. Lett. 554 (2012) 72-76. doi:10.1016/j.cplett.2012.10.018.

[4] A. Comment, B. van den Brandt, K. Uffmann, F. Kurdzesau, S. Jannin, J.A. Konter, P. Hautle, W.T. Wenckebach, R. Gruetter, J.J. van der Klink, Principles of Operation of a DNP Prepolarizer Coupled to a Rodent MRI Scanner, Appl. Magn. Reson. 34 (2008) 313-319. doi:10.1007/s00723-008-0119-3.

[5] J.H. Ardenkjaer-Larsen, S. Bowen, J.R.J.R. Petersen, O. Rybalko, M.S.M.S. Vinding, M. Ullisch, N.C.N.C. Nielsen, J.H. Ardenkjær-Larsen, S. Bowen, J.R.J.R. Petersen, O. Rybalko, M.S.M.S. Vinding, M. Ullisch, N.C.N.C. Nielsen, J.H. Ardenkjaer-Larsen, S. Bowen, J.R.J.R. Petersen, O. Rybalko, M.S.M.S. Vinding, M. Ullisch, N.C.N.C. Nielsen, Cryogen-free dissolution dynamic nuclear polarization polarizer operating at $3.35 \mathrm{~T}, 6.70 \mathrm{~T}$, and 10.1 T, Magn. Reson. Med. (2018). doi:10.1002/mrm.27537.

[6] M. Baudin, B. Vuichoud, A. Bornet, G. Bodenhausen, S. Jannin, A CryogenConsumption-Free System for Dynamic Nuclear Polarization at 9.4 T, J. Magn. Reson. (2018). doi:10.1016/J.JMR.2018.07.001.

[7] J.-H. Ardenkjaer-Larsen, G.S. Boebinger, A. Comment, S. Duckett, A.S. Edison, F. Engelke, C. Griesinger, R.G. Griffin, C. Hilty, H. Maeda, G. Parigi, T. Prisner, E. Ravera, J. van Bentum, S. Vega, A. Webb, C. Luchinat, H. Schwalbe, L. Frydman, Facing and Overcoming Sensitivity Challenges in Biomolecular NMR Spectroscopy., Angew. Chem. Int. Ed. Engl. 54 (2015) 9162-85. doi:10.1002/anie.201410653.

[8] B. Blümich, Beyond compact NMR, Microporous Mesoporous Mater. 269 (2018) 36. doi:10.1016/j.micromeso.2017.04.039. 
[9] K. Takeda, OPENCORE NMR: Open-source core modules for implementing an integrated FPGA-based NMR spectrometer, J. Magn. Reson. 192 (2008) 218-229. doi:10.1016/j.jmr.2008.02.019.

[10] K. Takeda, Highly Customized NMR Systems Using an Open-Resource, Home-Built Spectrometer, in: Annu. Reports NMR Spectrosc., 1st ed., Elsevier Ltd., 2011: pp. 355-393. doi:10.1016/B978-0-08-097072-1.00007-8.

[11] J.. Walton, M.S. Conradi, Probe tuning adjustments-Need they be in the probe?, J. Magn. Reson. 81 (1989) 623-627. doi:10.1016/0022-2364(89)90103-0.

[12] D.E. MacLaughlin, Coaxial cable attenuation in NMR sample coil circuits Single coil probe with transmission-line tuning for nuclear magnetic double resonance Coaxial cable attenuation in NMR sample coil circuits, Rev. Sci. Instrum. 60 (1989). doi:10.1063/1.1134560.

[13] P. Villa, J.J. Vaquero, S. Chesnick, J. Ruiz-Cabello, Probe efficiency improvement with remote and transmission line tuning and matching, Magn. Reson. Imaging. 17 (1999) 1083-1086. doi:10.1016/S0730-725X(99)00051-X.

[14] V.D. Kodibagkar, M.S. Conradi, Remote Tuning of NMR Probe Circuits, J. Magn. Reson. 144 (2000) 53-57. doi:10.1006/jmre.2000.2052.

[15] J.H. Ardenkjær-Larsen, B. Fridlund, A. Gram, G. Hansson, L. Hansson, M.H. Lerche, R. Servin, M. Thaning, K. Golman, Increase in signal-to-noise ratio of $>10,000$ times in liquid-state NMR., Proc. Natl. Acad. Sci. U. S. A. 100 (2003) 10158-63. doi:10.1073/pnas.1733835100.

[16] J.H. Ardenkjaer-Larsen, A.M. Leach, N. Clarke, J. Urbahn, D. Anderson, T.W. Skloss, Dynamic nuclear polarization polarizer for sterile use intent., NMR Biomed. 24 (2011) 927-32. doi:10.1002/nbm. 1682.

[17] A. Capozzi, M. Karlsson, J.R. Petersen, M.H. Lerche, J.H. Ardenkjaer-Larsen, Liquid-State 13 C Polarization of $30 \%$ through Photo-Induced Non-Persistent Radicals, J. Phys. Chem. C. (2018) acs.jpcc.8b01482. doi:10.1021/acs.jpcc.8b01482.

[18] D. Pozar, Microwave engineering, Fourth ed., John Wiley \& Sons, Inc., Hoboken, NJ, 2012. 
[19] J.M.O. Vinther, V. Zhurbenko, M.M. Albannay, J.H. Ardenkjaer- Larsen, Design of a local quasi-distributed tuning and matching circuit for dissolution DNP cross polarization, Solid State Nucl. Magn. Reson. accepted (n.d.).

[20] G. Giovannetti, F. Frijia, L. Menichetti, J.H. Ardenkjaer-Larsen, V. Hartwig, D. De Marchi, V. Positano, L. Landini, M. Lombardi, M.F.F. Santarelli, Coil Sensitivity Estimation with Perturbing Sphere Method: Application to $13 \mathrm{C}$ Birdcages, Appl. Magn. Reson. 42 (2012) 511-518. doi:10.1007/s00723-012-0323-Z.

[21] J.-C. Ginefri, E. Durand, L. Darrasse, Quick measurement of nuclear magnetic resonance coil sensitivity with a single-loop probe, Rev. Sci. Instrum. 70 (1999) 4730-4731. doi:10.1063/1.1150142. 


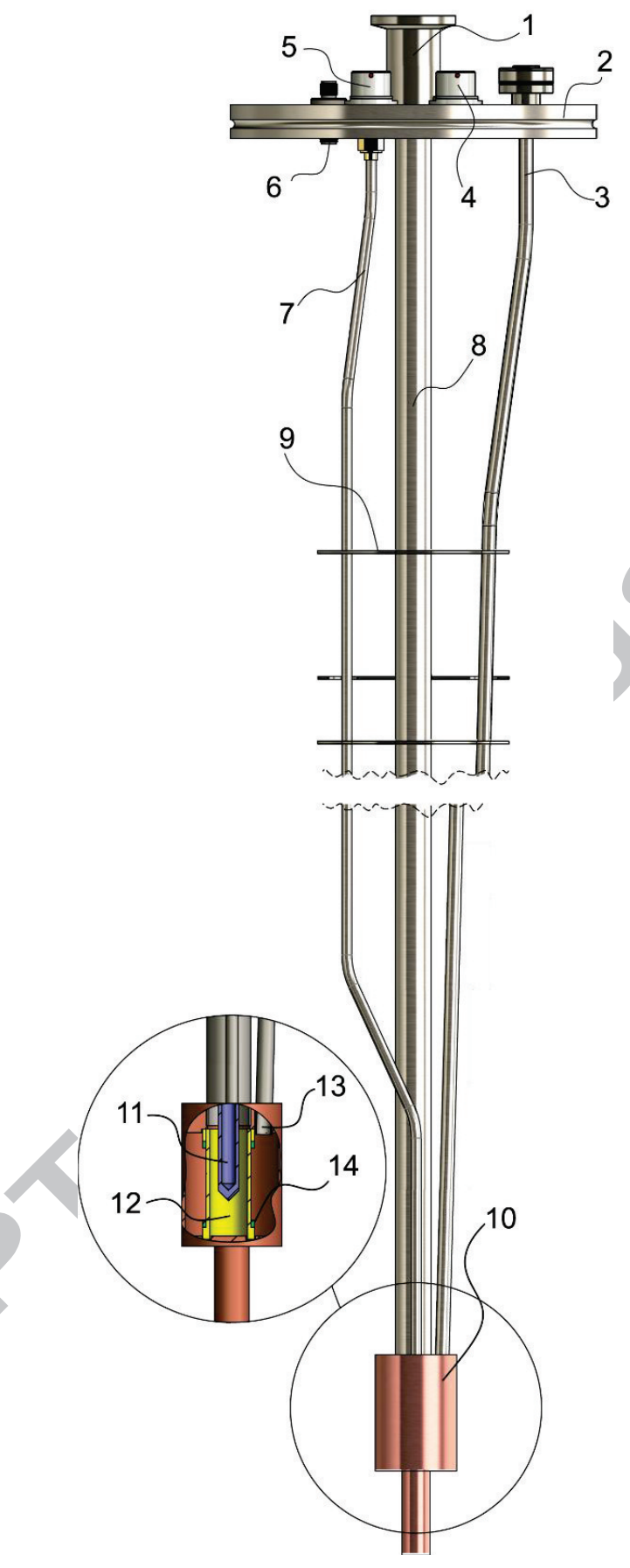

Figure 1: Drawing of dDNP probe. 1. sample loading port, 2. ISO-F100 flange, 3. waveguide, 4. thermometer connector, 5. helium level connector, 6. hepatic SMA connector, 7. UT141SS-C-P coaxial cable, 8. Sample tube, 9. thermal baffle, 10. overmoded cavity, 11. sample vial (purple), 12. coil former (yellow), 13. Waveguide outlet and 14. Alderman-Grant coil (green). Not illustrated: Allen-Bradley resistors, Cernox sensor and second hepatic SMA connector (positioned behind component 5.) 


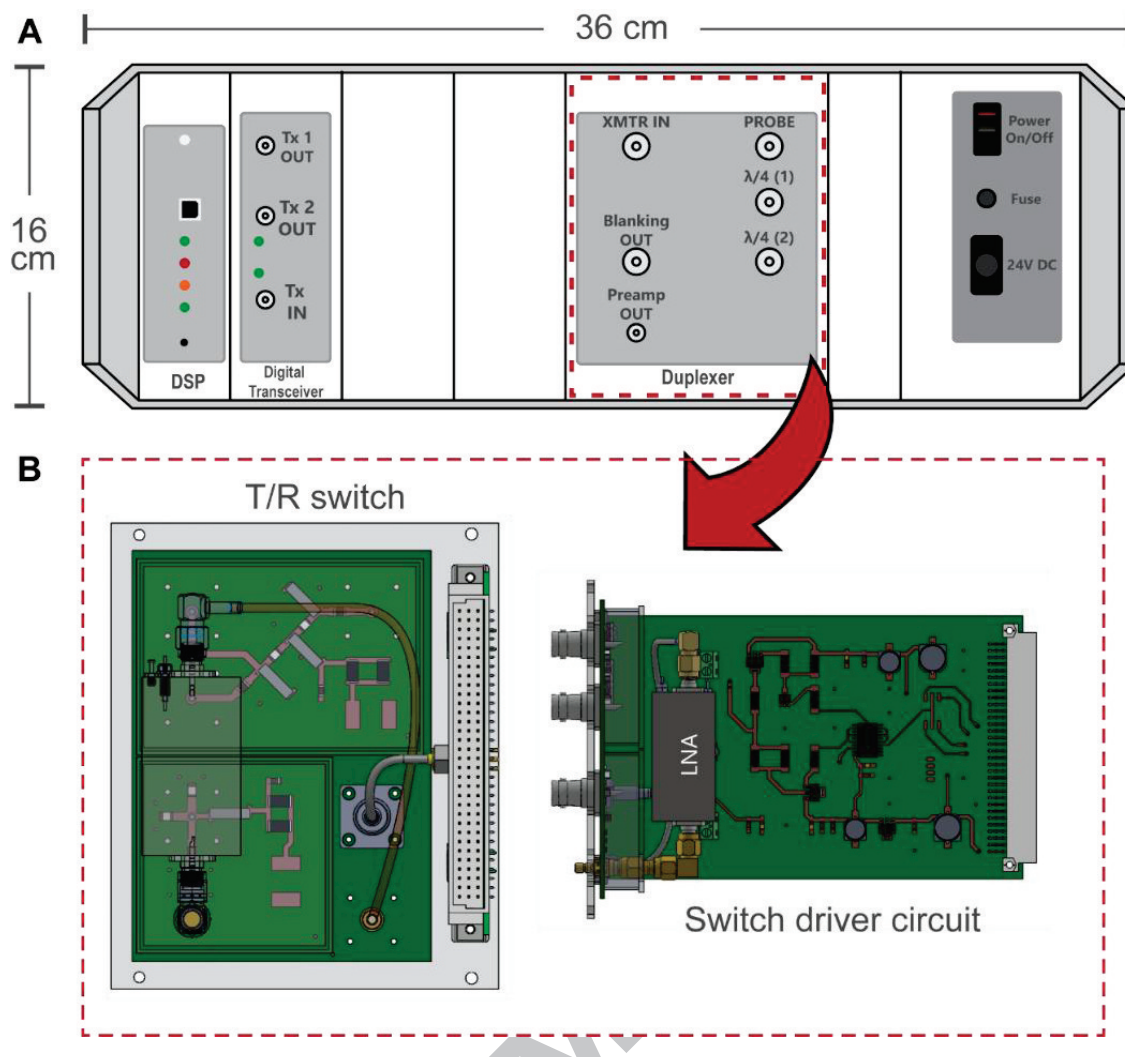

Figure 2a: Illustration of an integrated duplexer in $\mathrm{Kea}^{2}$ spectrometer. The duplexer consists of two printed circuit boards ( $T / R$ switch and switch driver circuit). $b$. The T/R switch is enclosed by two aluminium shields to mitigate electromagnetic interference. 


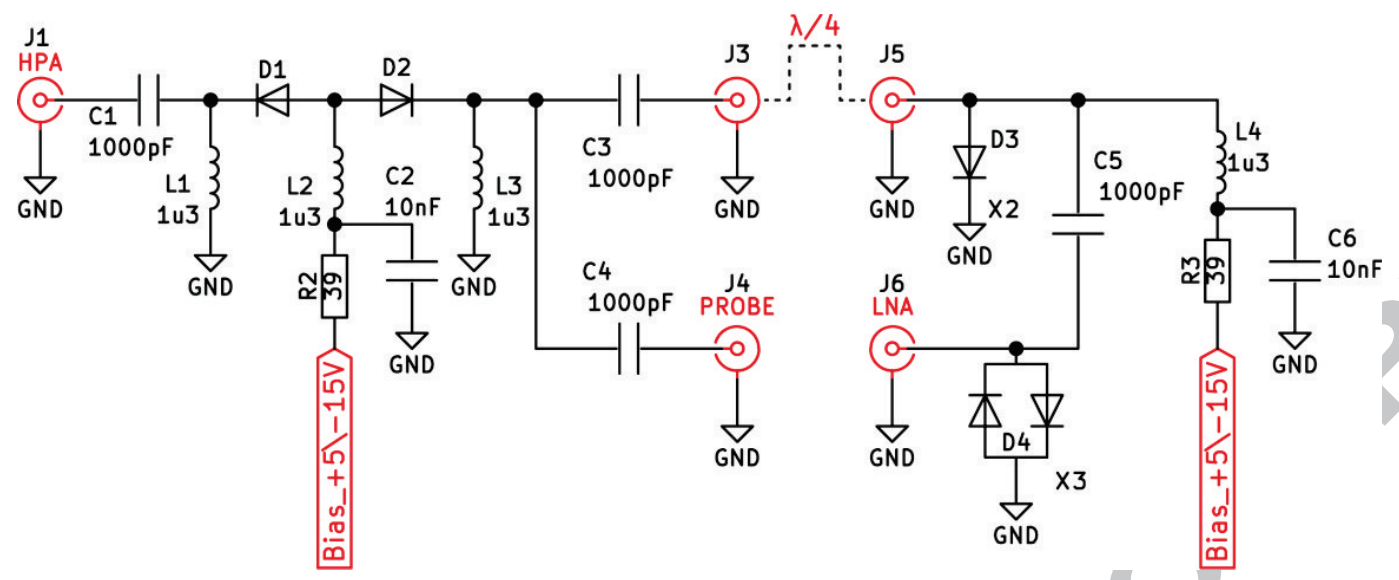

Figure 3: Schematic of T/R switch. Diodes D1-D3 in combination with N4 cable provide isolation between the LNA input $J 6$ and HPA J1. The source bias current is determined by resistors R2 \& R3 and fed via RFC L1-L4. Anti-parallel diodes $D 4$ reduce $L N A$ saturation. C1, C3-5 are by-pass capacitors, while C2, C6 are decoupling capacitors.

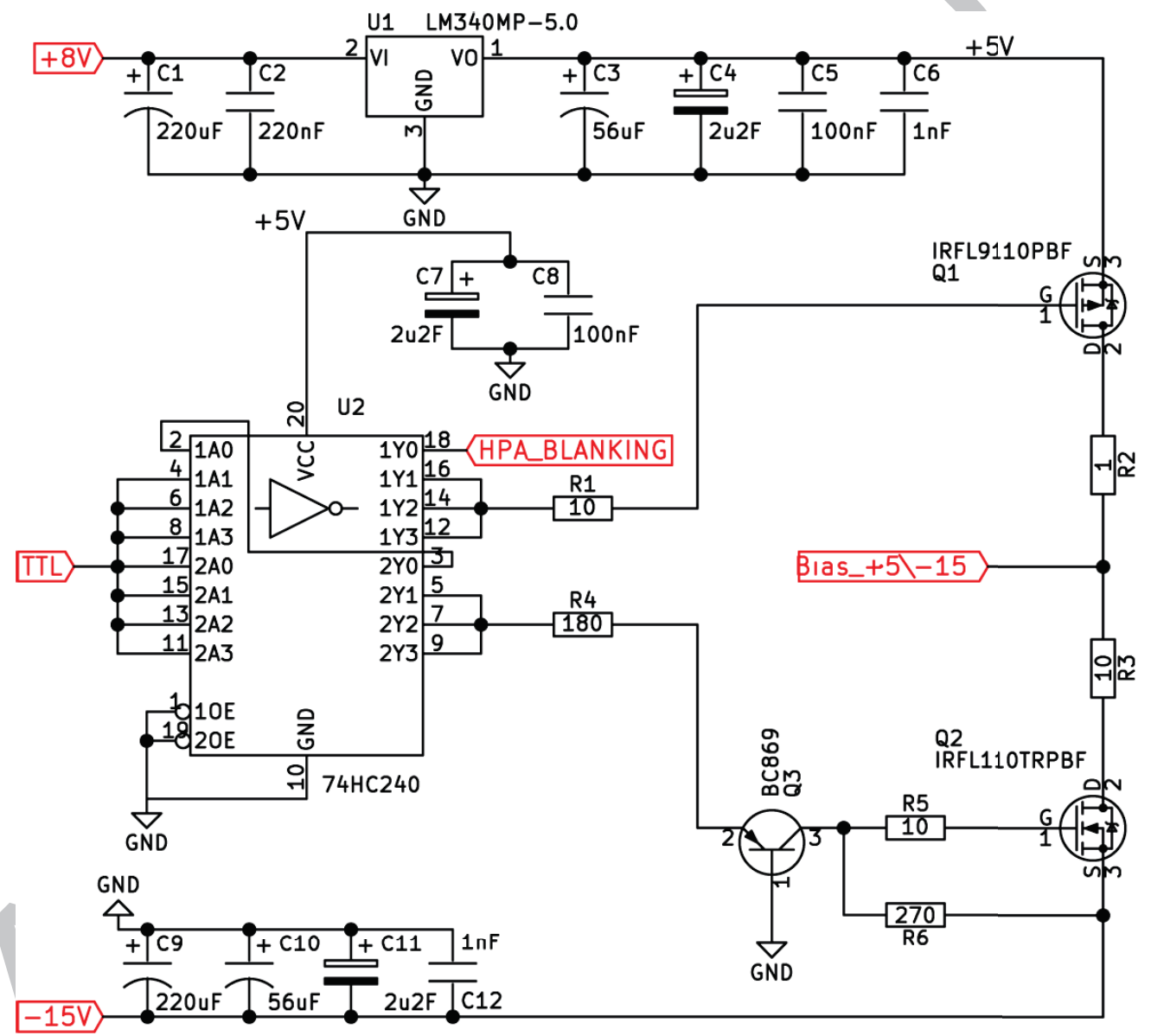

Figure 4: Schematic of T/R switch driver. U2 buffers TTL from backplane to switching transistors Q1 \& Q2 (via Q3). Capacitors C1-C12 are bypass capacitors. Resistors R4 \& R6 ensure appropriate transistors biasing. Bias node is coupled to T/R switch via RG316 coaxial cable. R1 and R5 prevent MOSFET oscillation. 
A
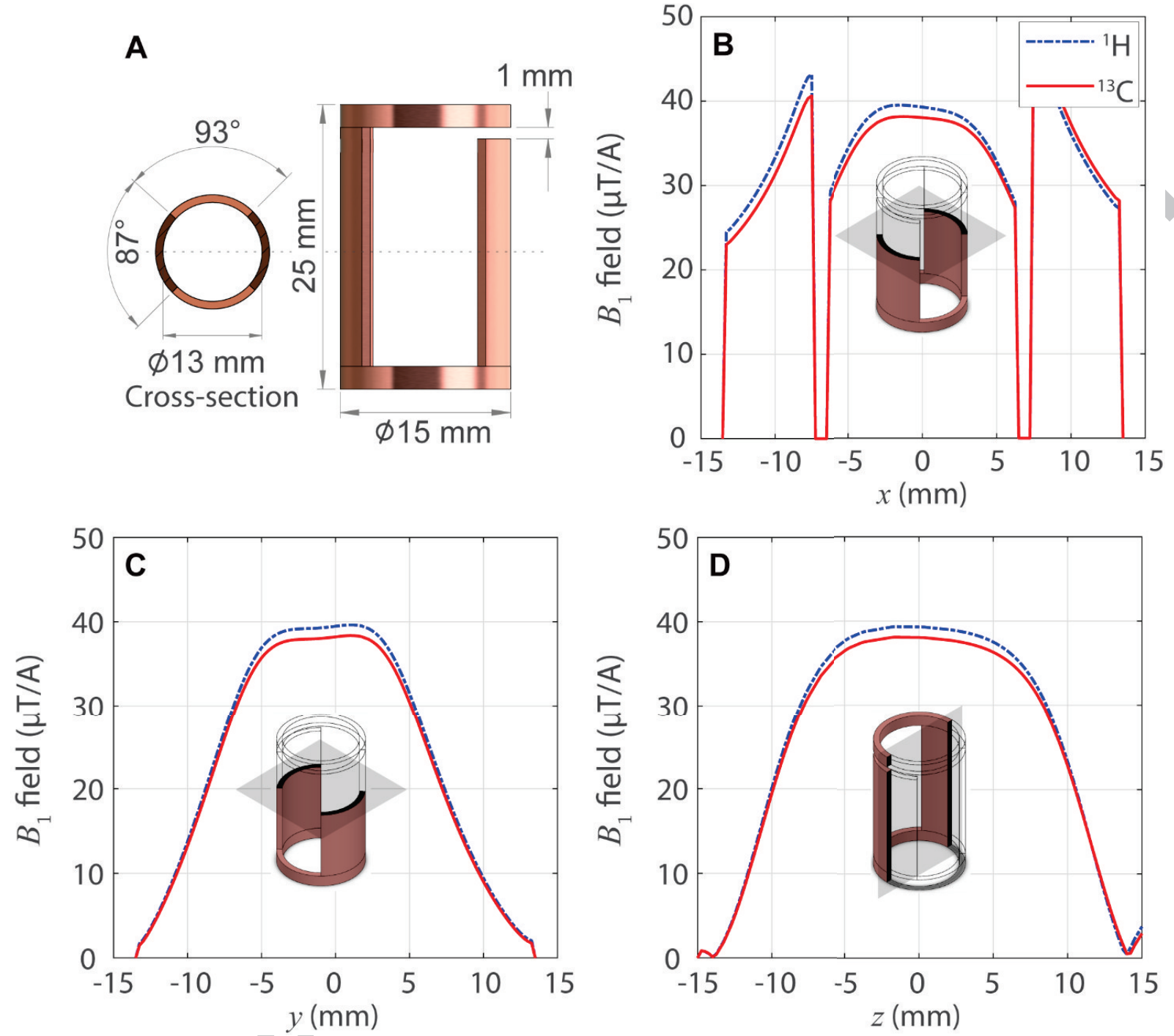

Figure 5: (a) CAD illustration of Alderman-Grant sample coil from side and cross-section. (b-c) Simulated $1 D$ magnetic field amplitude profiles along $x, y$ and $z$ centerlines of the sample coil. Difference in curves due to frequency dependent dispersion in the coil conductor current distributions. 


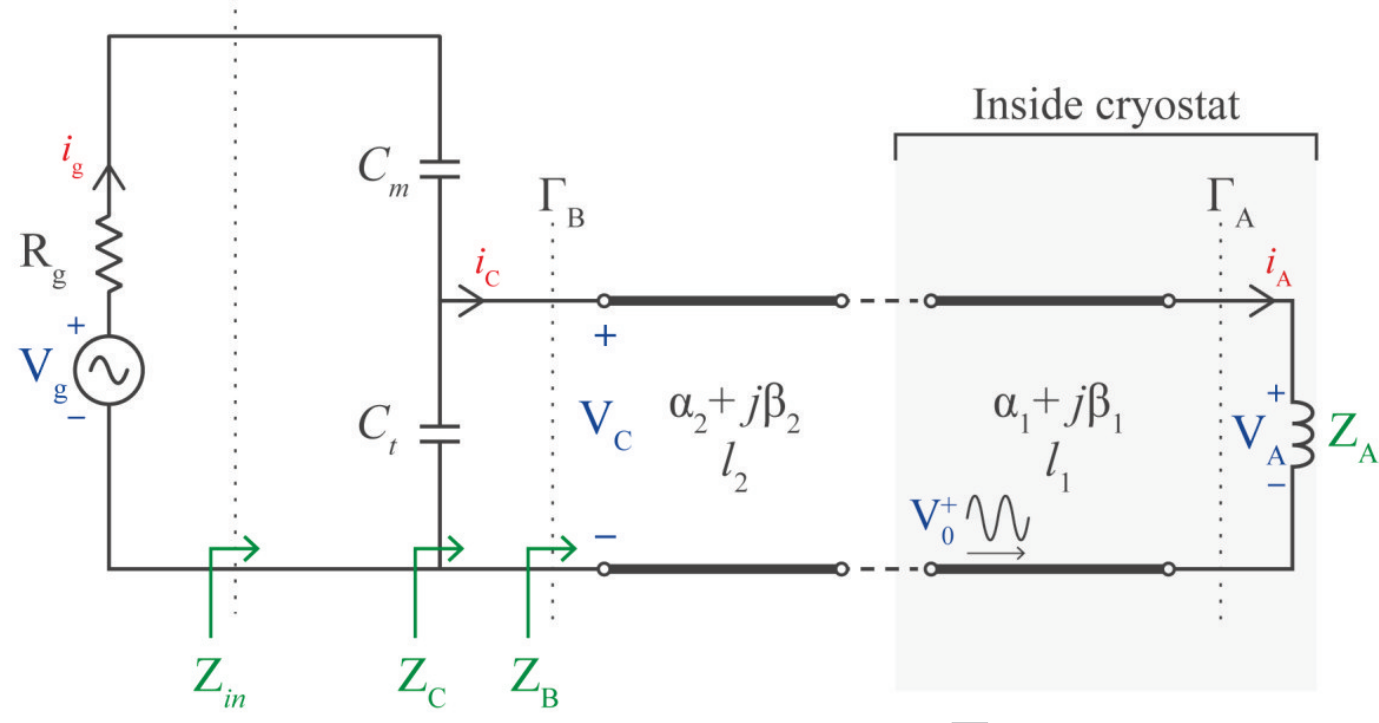

Figure 6: Circuit model of resonant circuit employing remote TM scheme. The sample coil and UT141-SS-C-P coaxial cable are inside the cryostat and couple to an RG316 cable at room temperature via hermetic SMA connector. Two capacitors TM the observed impedance to the HPA impedance.

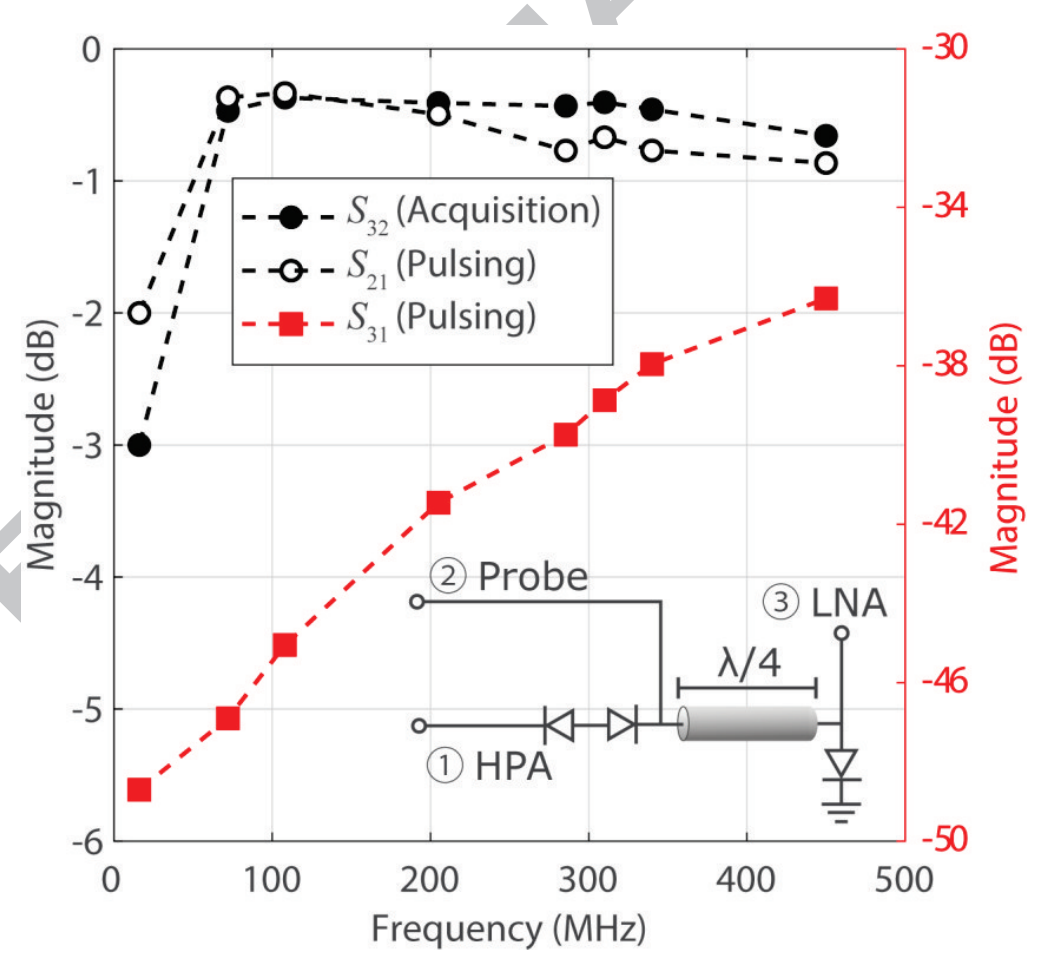

Figure 7: Scattering parameters between the HPA, LNA and probe (as depicted in inset circuit).Isolation between the HPA and LNA $\left(S_{31}\right)$ as well as insertion loss between the HPA and probe $\left(S_{21}\right)$ were measured during pulse mode $\left(V_{\text {bias }}=+5 \mathrm{~V}\right)$. Insertion loss between the probe and LNA $\left(S_{32}\right)$ was measured during acquisition mode. The transmission line was replaced accordingly to resemble $N / 4$ at the measured frequency (length was kept as short as practically possible). 

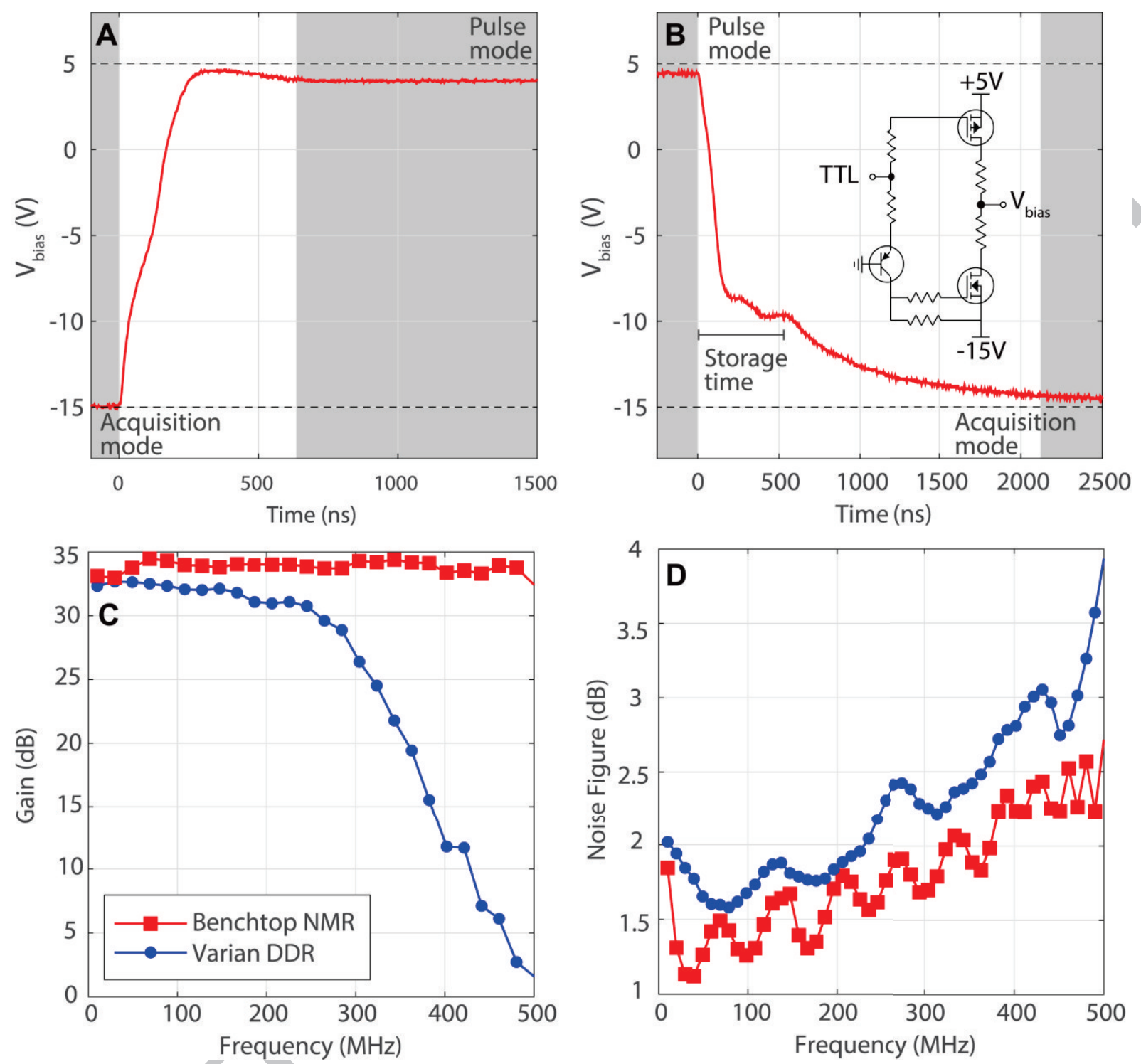

Figure 8: Transient bias voltage measured at node $V_{\text {bias }}$ as depicted by inset circuit. TTL signal initiates $V_{\text {bias }}$ change between $5 \mathrm{~V}$ and $-15 \mathrm{~V}$. (a) Switching between acquisition to pulse takes $690 \mathrm{~ns}$ to reach steady-state voltage. (b) Switching between pulse to acquisition mode takes $\sim 2400 \mathrm{~ns}$ of which $\sim 550 \mathrm{~ns}$ are storage time (PIN diode discharging due to bias voltage as oppose to charge gradient diffusion). (c-d) LNA gain and noise figure measurements. Both amplifiers isolated from hosting circuit and tested on the bench. 

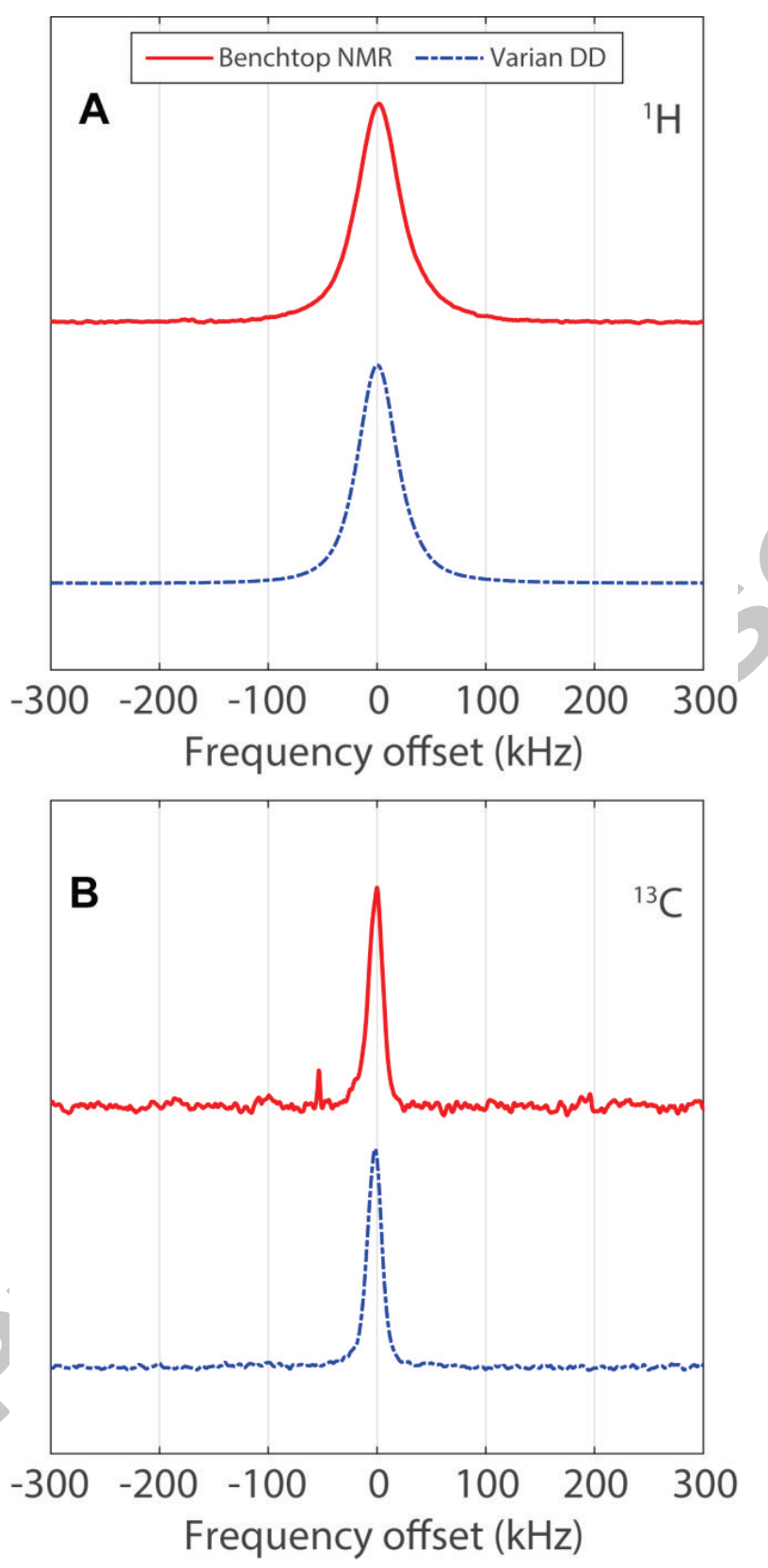

Figure 9: ${ }^{1} \mathrm{H}$ and ${ }^{13} \mathrm{C}$ phased spectra as acquired using the benchtop NMR and DD spectrometers for $100 \mu \mathrm{L} 4.5 \mathrm{M}[1$ ${ }^{13}$ C]urea in 5:4:1 glycerol-d $d_{8}: D_{2} \mathrm{O}: \mathrm{H}_{2} \mathrm{O}$ (v:v) sample with $40 \mathrm{mM}$ TEMPOL. 


\section{ACCEPTED MANUSCRIPT}

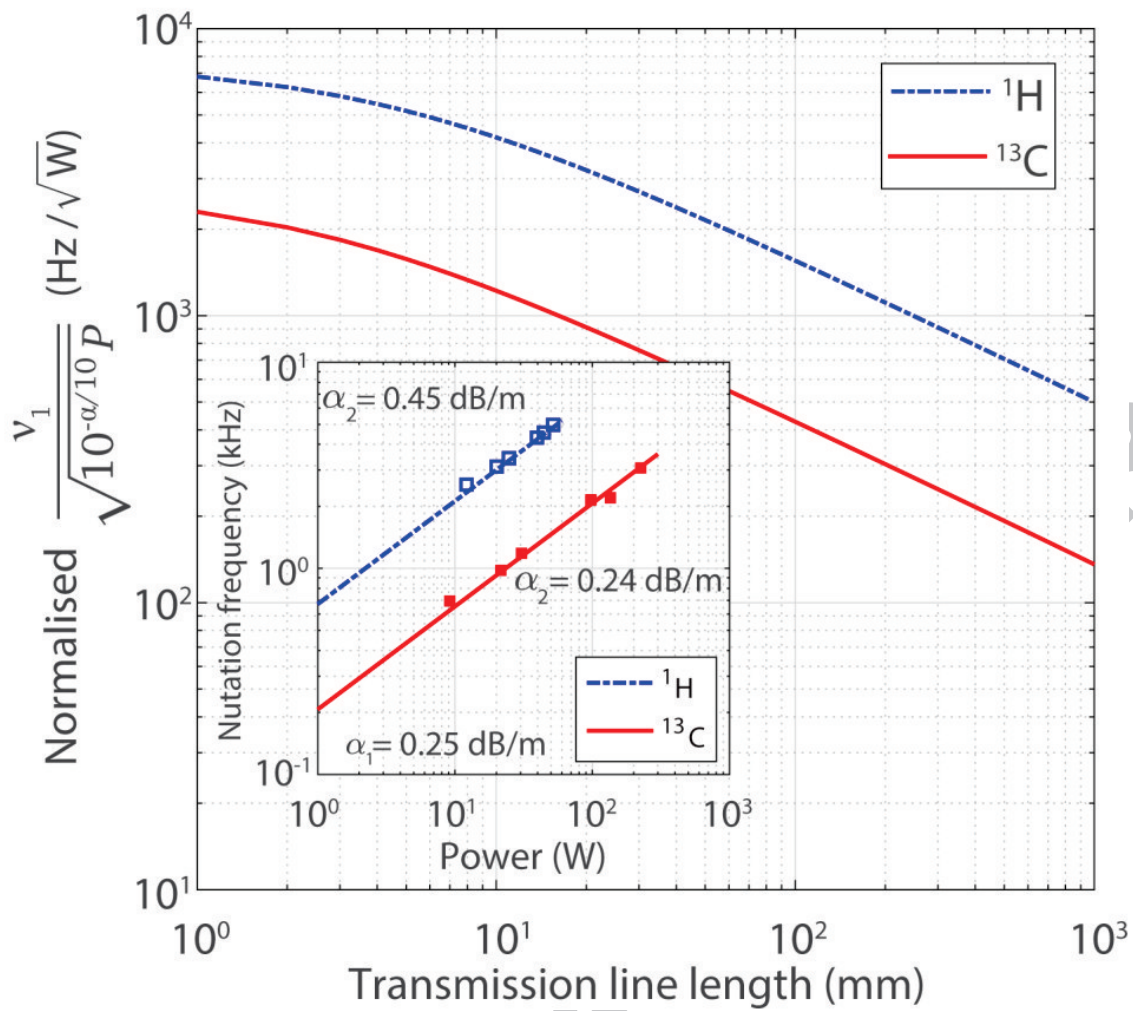

Figure 10: Normalized nutation frequency as a function of line attenuation $\alpha$ per squareroot power against transmission line length. Values based on de-embedded measured sample coil impedance. Inset graph illustrates nutation frequency for varying pulse powers using the dDNP probe circuit. Experimentally verified $v_{1}$ indicated by $\square$ and $\square$. 
1. Standalone two channel, modular benchtop spectrometer with integrated duplexer able to fulfil high field solid and liquid state NMR applications up to $450 \mathrm{MHz}$ with comparable SNR sensitivity to dedicated high-resolution spectrometers.

2. Quantitative investigation of tuning and matching scheme and their effect on achievable nutation frequency.

3. Closed-form equations to estimate the magnetic field magnitude in any given sample coil are presented. 

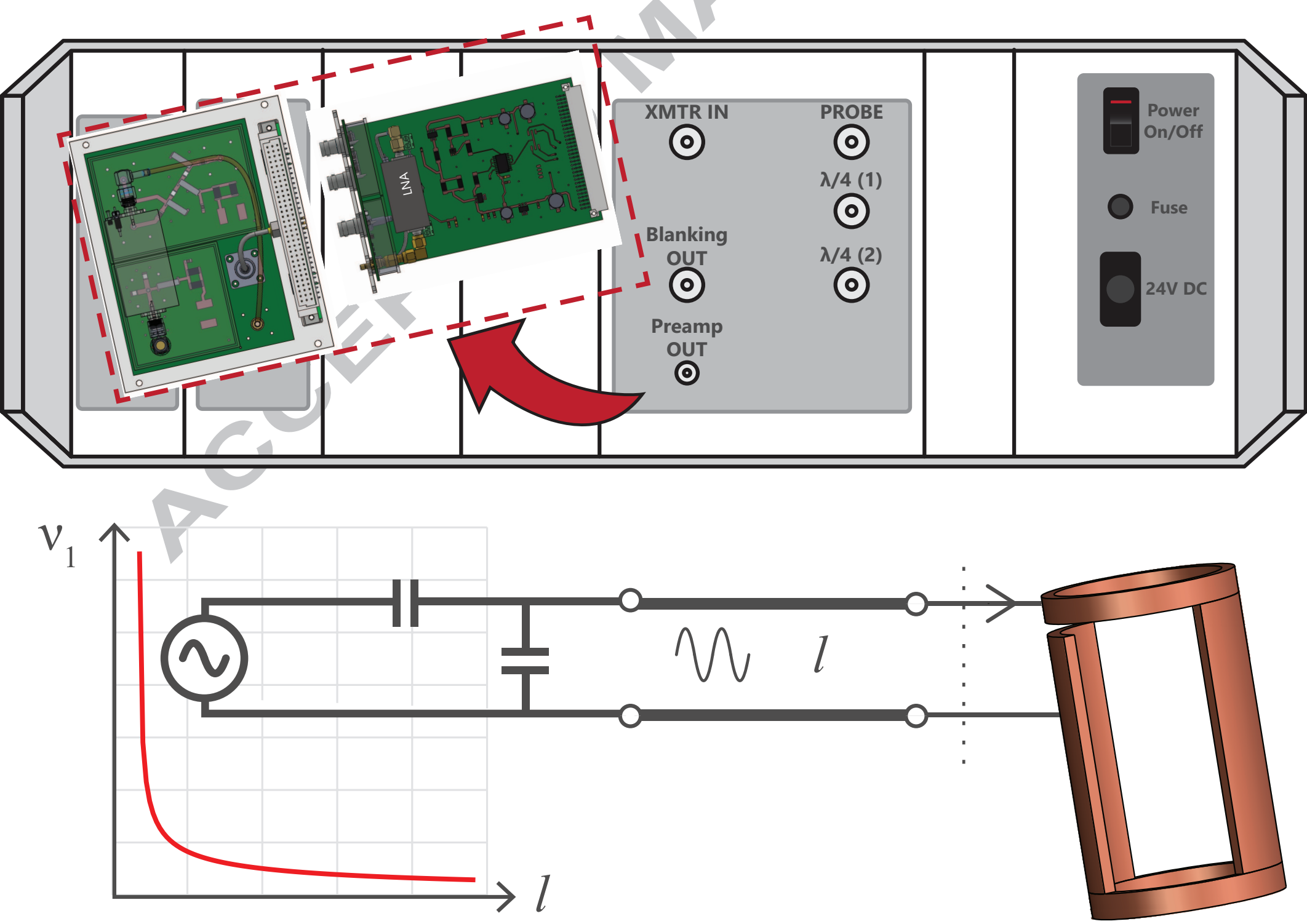